Journal of Sustainable Development of Transport and Logistics

journal home page: https://jsdtl.sciview.net

Ahmed, M. M., Gaweesh, S., Ksaibati, K., \& Rahman, Md. H. (2018). Assessing the impact of the compliance rate and daytime running lights penetration on the safety effectiveness of regulatory headlight use signs. Journal of Sustainable Development of Transport and Logistics, 3(1), 6-21. doi:10.14254/jsdtl.2018.3-1.1.

\title{
Assessing the impact of the compliance rate and daytime running lights penetration on the safety effectiveness of regulatory headlight use signs
}

\author{
Mohamed M. Ahmed (D), Sherif Gaweesh ${ }^{(D)}$, Khaled Ksaibati ${ }^{(D)}$,
}

Md Hamidur Rahman

University of Wyoming,

Laramie, Wyoming, 82071

Department of Civil and Architectural Engineering

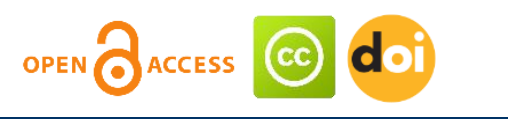

Article history:

Received: December 12, 2017

1st Revision: February 7, 2018

Accepted: March 21, 2018

\section{DOI:}

10.14254/jsdtl.2018.3-1.1

\begin{abstract}
While Daytime Running Lights (DRLs) are proven to increase vehicle conspicuity during various times of the day, their safety effectiveness is still debatable. This study utilized various statistical techniques and a field study to assess the impact of the compliance rate, and the penetration of the Daytime Running Lights (DRLs) technology on the safety efficacy of regulatory headlight use signs. Daytime head-on and opposite sideswipe multivehicle crashes for Daytime Running Lights and non-DRLs equipped passenger vehicles on mountainous rural two-way highway sections with and without regulatory headlight use signs were examined in a matched case control design. Preliminary analysis showed that only $23 \%$ of vehicles involved in crashes on the study sections were equipped with DRLs. Although results from the odds ratios and ratios of odds ratios indicated some safety benefits of the headlight use signs, the safety benefits were statistically insignificant. The study concluded that the low compliance rate of $12 \%$ affected the safety effectiveness of the regulatory headlight signs. Transportation agencies should have different considerations when evaluating the safety effectiveness of compliance- and behavioral-based countermeasures.
\end{abstract}

Keywords: Daytime Running Lights, safety, headlight signs, safety effectiveness.

\section{Introduction}

Daytime Running Lights (DRLs) are a technology used to enhance traffic safety by decreasing certain types of collisions. The safety benefit of DRLs might be attributed to the increase of vehicle conspicuity during daytime, dusk, and dawn. While several studies showed a positive safety effect of using DRL during daytime, other studies showed that DRLs does not have a significant safety benefits to

Corresponding author: Mohamed M. Ahmed

E-mail:mahmed@uwyo.edu

This open access article is distributed under a Creative Commons Attribution (CC-BY) 4.0 license. 
reduce certain types of crashes. The effect of using DRL is still up to debate (Rumar, 1980). Although many studies in the literature indicated some safety benefits of DRL, nearly the most of these studies have design or analysis weaknesses. Design and analysis flaws may result in inaccurate estimates of the true safety benefit of DRLs (Williams et al., 1995). Elvik et al., 1993, also stated that the evidence to conclude the safety effectiveness of DRL was not firm from a scientific point of view. A reduction of 10 to 15 percent in the number of multivehicle daytime crashes using 17 studies was obtained using a logodds meta-analysis (Elvik, 1996). Some safety benefits of DRLs were concluded in a study by the National Highway Traffic Safety Administration (NHTSA) in 2004 (Tessmer, 2004). Six years of data between 1995 and 2001, from the Fatality Analysis Reporting System (FARS) and the General Estimate System (GES) were analyzed utilizing the generalized simple odds. Utilizing the aforementioned conventional statistical technique, DRLs were proven to reduce certain types of crashes. The study showed a similar 5\% reduction for both opposite direction daytime fatal crashes and opposite direction/angle daytime non-fatal crashes. Crashes involving non-motorists were also reduced by $12 \%$, i.e. pedestrians and cyclists, in addition to a $23 \%$ reduction in opposite fatal crashes of passenger vehicles with motorcycles. It is worth mentioning that although the study controlled for a variety of factors other than DRLs; however, none of these results were found to be statistically significant using simple odds ratio.

On the other hand, contradicting findings were concluded in a large-scale study conducted by the NHTSA in 2008. Except for a 5.7\% reduction in the light trucks/vans crashes involved in multi-vehicles crashes, the study showed that DRLs were statistically insignificant in reducing the studied crash types (Wang, 2008). Elvik (1993) showed that the total number of multiple vehicles, pedestrian, and twilight crashes were not reduced (Elvik et al., 1993). Also, the rear end crashes increased by $20 \%$. It was also stated that daytime multivehicle crashes were reduced only during the summer by about $1.5 \%$. Another study concluded that the data fail to show a clear effect of DRL (Theeuwes \& Riemersma, 1995).

Roadways safety and operation are severely affected by inclement weather events such as fog, snow, ground blizzard, slush, rain, and strong wind, etc. Inclement weather has a negative effect on pavement surface condition, vehicle performances, visibility, and drivers' behavior. Road users' characteristics are among the most important elements influencing the driving tasks. The ability to perceive and distinguish objects in motion, relative to the eye acuteness or clearness of vision, and the driver's reaction process are of utmost importance for safe driving.

Daytime Running Lights (DRLs) were first deployed in the Scandinavian countries to increase visual contrast between vehicles and their background, enhancing their noticeability and detectability. Headlight use signs are regulatory signs used as a safety countermeasure to reduce certain type of daytime crashes. It mandates motorists to turn on their low-beam headlights. Vehicles equipped with DRLs should also comply with the headlight sign by turning on their low beam headlights manually. It is worth mentioning that there are functional issues with using the automatic DRLs only. This is especially related to the rear end detectability of the vehicle, as the taillights do not come on until the low beam headlights are turned on.

Both headlights and taillights might be more effective at hazardous roadway sections designated as safety improvement zones. Taillights could be useful especially in adverse weather conditions where a reduction in visibility is encountered. It could help in identifying the roadway alignment for following vehicles.

Previous studies have been unable to demonstrate the true safety effect of using DRLs due to unsuitability to adopt advanced statistical techniques (Wang, 2008). Alternative approaches should be utilized to re-examine the safety effectiveness of DRLs as suggested by the NHTSA. Moreover, further investigation for mandating a regulation to turn on headlights on certain sections of rural two-lane highways at certain times of the year and weather conditions is needed. Headlight signs are considered behavioral-based countermeasure that require drivers to comply and turn on their vehicles' headlights manually. This behavioral-based strategy is different from the newly technology-based standards as the DRL. It is worth mentioning that some states in the US have mandated a new regulation of "Wipers On, Headlights On". While the regulatory headlight sign countermeasure may help in better detectability of vehicles on mountainous roadways, "Wipers On, Headlights On" new traffic regulation may help reducing crashes in adverse weather conditions.

The main objective of this study is to evaluate the impact of the presence of DRLs on the safety effectiveness of regulatory headlight signs. In addition, the study investigates the effect of compliance 
rates for motorists on the safety benefits of regulatory headlight signs on mountainous rural two-lane highways in Wyoming. The following sections illustrate the review of the literature, the description of the headlight signs locations, the procedures of preparing the data, statistical methodologies, results, limitations, and conclusions.

\section{Literature review}

In early 1990, several European countries (Denmark, Finland, Hungary, Norway, and Sweden) and Canada mandated vehicles to always turn on their headlights as a road safety measure. Various studies have proven that DRLs are a statistically effective measure to reduce multiple-vehicle crashes in daytime, dawn, and dusk. Due to the low ambient light levels in Ireland, where it is permanently dark during the winter, the use of low-beam headlights is encouraged during daytime. The use of DRLs in Italy, Hungary, and Romania is required outside populated areas, i.e., rural areas, at all times. Turning on low-beam headlights at daytime on certain roads at certain times of year were required in the past in many European countries including Germany, Spain, and France (Elvik, 1993; Knight et al., 2006; Hansen, 1993; Holló, 1998).

Canada Motor Vehicle Safety Standard (CMVSS) required all new vehicles made or imported after January 1990 to come equipped with automatic DRLs as a standard safety feature. Automakers opposed the DRLs new laws because of the extra cost of adding an additional front lighting device, warranty, and the increased potential of bulb replacement. Later on, the use of reduced-wattage high beam headlamps was allowed. In addition, light color from white to amber or yellow was also permitted (Arora et al., 1994). In 2011, all passenger cars and vans were required to be equipped with DRLs according to the European Union Directive (EUD). Recently in 2012, the mandate was extended to include trucks.

Permitting to manufacture vehicles equipped with DRLs were first discussed in the United States in 1990. However, it was objected by the National Highway Traffic Safety Administration (NHTSA) based on high-intensity that might lead to potential glare issues and problems with turn signal masking. In 1993, DRLs were permitted, but not mandated, in the United States (National Highway Traffic Safety Administration, 2000). General Motors (GM) equipped most of its vehicles starting 1995 to reduce the automotive manufacturing variation in the North American market. By 1997, all GM vehicles come standard -equipped with DRLs. Federal Motor Vehicle Safety Standard (FMVSS) No. 108 limits the DRLs maximum light intensity output to 7,000 candelas, which represents $10 \%$ of the standard high-beam headlamp intensity. Because of plentiful complaints regarding the glare resulting from the DRLs, the intensity output was further reduced to 1,500 candelas in 1998. In addition to glare, a study showed that DRLs might make motorcycles, pedestrians, and bicyclists less conspicuous and that DRLs would have an environmental impact (Pierowicz et al., 2011).

Beyond any doubt, many studies have found that DRLs increase vehicle conspicuity especially during inclement weather conditions such as rain or snow. Sparks et al. (1993) stated that a $28 \%$ reduction in daytime-running-light relevant daytime two-vehicle crashes and 15\% reduction in crash types (Sparks et al., 1993). Farmer and Williams (2002) analyzed multiple-vehicle daylight crashes in nine states over 4 years (Farmer \& Williams, 2002). Analysis showed that a reduction of $3.2 \%$ in multiple vehicle crashes was observed.

A study conducted by the FHWA recommended to standardize the headlight signs due to the wide variation in the legends used for signs that require road users to turn on their vehicle headlights under certain conditions (Wainwright et al., 2005). Moreover, the regulations of these signs depend on laws that vary from State to State. As an example, Wyoming State requires motorists to turn on low-beam when having rain or any adverse weather conditions. On the other hand, according to the Colorado driving handbook, the use of headlights in adverse weather conditions is not mandated. Due to the variation of regulations across the nation, the FHWA added a new section titled "Headlight Use Signs" in the latest edition of the (MUTCD, 2009), to provide uniformity of the sign wording and design. The Federal Highway Administration (FHWA) replaced the "TURN OFF HEADLIGHTS" sign with "END DAYTIME HEADLIGHT SECTION" as it might provide a misleading message to road users during nighttime.

According to the FHWA Office of Safety, lane departure crashes represent 53\% of annual fatal crashes in 2015 (https://safety.fhwa.dot.gov/roadway_dept/, 01/02/2017). A lane departure crash includes runs off the road crashes, opposite direction sideswipe crashes and head-on crashes. The 
Wyoming Strategic Highway Safety Plan (SHSP), 2012, identified six categories which have high potential of crash reduction (WSHSP, 2012). The identified six categories were: 1) roadway departure crashes, 2) use of safety restraints, 3) impaired driving, 4) speeding, 5) young drivers, and 6) curve crashes. Among the six determined categories, lane departure consistently produced the highest number of crashes from 2002 to 2010 as shown in Figure 1.

The SHSP indicated that lane departure crashes comprised 72 percent of all severe crashes for the years 2008 - 2010. As a result, the Wyoming SHSP considered these types of crashes as a priority to reduce fatal and serious injury crashes. These types of crashes are often dominated by distracted driving, failure to identify surrounding vehicles, and poor visibility due to inclement weather conditions.

Figure 1: Wyoming's critical crashes (Incapacitating injury and fatal) $2002-2010$

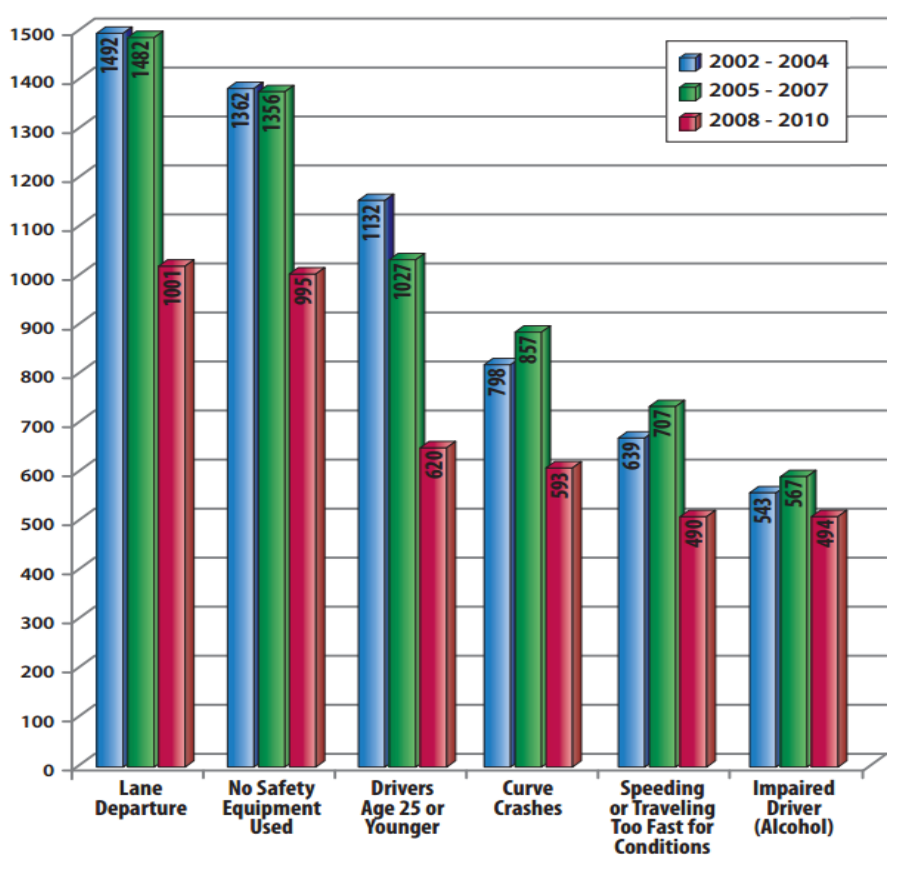

Source: Wyoming Strategic Highway Safety Plan, 2012

\section{Locations and description of headlight signs}

Seven roadway sections in Wyoming utilized the MUTCD "Turn on Your Headlights for Safety Next XX Miles" headlight sign as shown in Figure 2. All roadways having the headlight signs are classified as principal or minor arterial two-way two-lane roads. The first implementation of the signs was back in 1994 on US287/WY789. The latest signs were implemented in 2012 on WY220 and WY59.

One of the daunting tasks in this study was to identify non-treated sections that, to some extent, acceptably match the headlight sections. Annual Average Daily Traffic (AADT) as the main exposure factor affecting the crash frequency and rate was the first utilized criterion to identify comparable nontreated sites (sites with no headlight signs) (Qin et al., 2004; HSM, 2010; Dong et al., 2015; Chen et al., 2016). Because two-way two-lane highways in Wyoming are characterized by their challenging mountainous geometry, horizontal and vertical characteristics were the second criterion to identify non-treated sites. The AADT, vertical, and horizontal characteristics of all sections utilized in this study were investigated and summarized in the following sections. 


\section{Figure 2: Headlight sign locations in Wyoming}

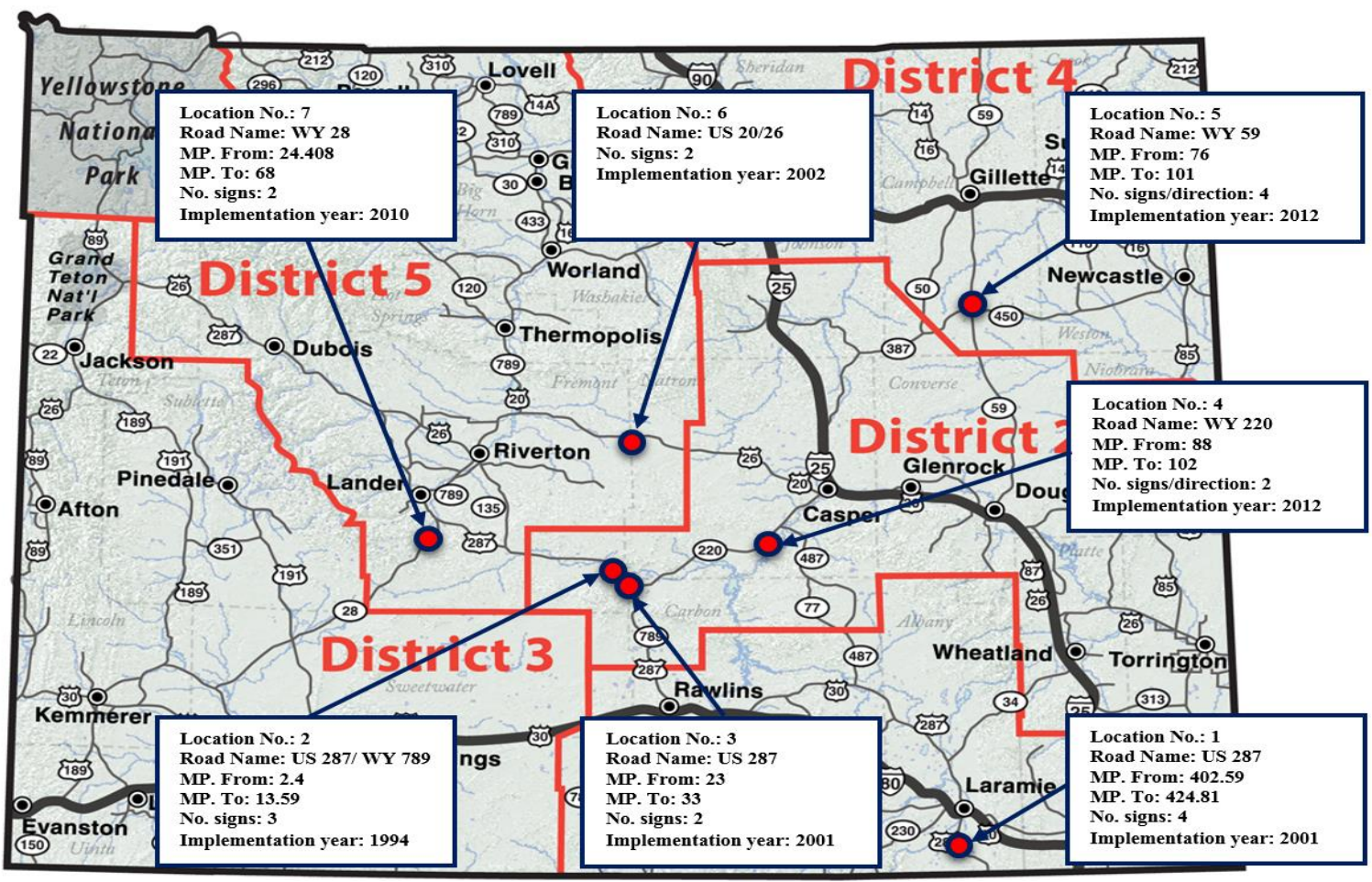

Traffic Characteristics: Table 1 shows the Annual Average Daily Traffic (AADT), and the Annual Average Daily Truck Traffic (AADTT) on the headlight sections. AADTs were extracted from the Wyoming Department of Transportation, Automatic Traffic Recorder Report 2013 (Automatic Traffic Recorder Report, 2013). The traffic volume on WY59 was found to be the highest among all locations and was characterized by high percentage of truck traffic in both directions. The traffic on US287 was found to be diverse in composition with a similar proportion of in-state and out-of-state vehicles. Passenger vehicles dominated the roadway traffic with fairly low percentage of truck traffic. The traffic on WY220 was predominantly from Wyoming with occasionally out-of-state vehicles.

\section{Table 1: Traffic Counts in the Headlight Sign Sections in Wyoming}

\begin{tabular}{|c|c|c|c|c|c|}
\hline \multirow{2}{*}{ Road Name } & \multicolumn{2}{|c|}{ Section } & \multirow{2}{*}{ Length (mile) } & \multirow{2}{*}{ Average 2013 AADT (vpd) } & \multirow{2}{*}{$\begin{array}{c}\text { Average } 2013 \text { AADTT } \\
\text { (vpd) }\end{array}$} \\
\hline & Begin M.P. & End M.P. & & & \\
\hline US 287 & 402.59 & 424.81 & 222.22 & 3329 & 603 \\
\hline US 287/WY 789 & 2.4 & 13.59 & 11.19 & 748 & 96 \\
\hline US 287 & 23 & 33 & 10 & 967 & 129 \\
\hline WY 220 & 88 & 102 & 14 & 3143 & 642 \\
\hline WY59 & 76 & 101 & 25 & 4332 & 792 \\
\hline US $20 / 26$ & 50.69 & 100 & 49.31 & 2480 & 413 \\
\hline WY 28 & 24.408 & 68.199 & 43.80 & 1347 & 216 \\
\hline
\end{tabular}

Sections with comparable AADT was identified as non-treated sections. The average AADT for the headlight sections was 2369 vpd for the 12 years of crash data (2003-2014). The average AADT for the non-treated sites was $2170 \mathrm{vpd}$. Also, the standard deviation for both the treated and non-treated sites were 1130 and $1300 \mathrm{vpd}$, respectively. An unequal sample sizes and unequal variances t-test was conducted to check whether the two samples are similar or not. The result showed that the two samples' means did not have significant difference ( $\operatorname{tAADT}=0.354, \mathrm{P}=0.731$ ).

Vertical Alignment Properties:

Table 2 provides description of the vertical alignment characteristics for the treated and nontreated sections. The number of vertical curves per mile was the main criterion in selecting the nontreated sections among the vertical characteristics. The characteristics of vertical alignment were nearly similar between the treated and the non-treated sections. The numbers of crest curves per mile for the 
treated sections was 1.44 compared to 1.31 for the non-treated locations (tCrest $=0.957, \mathrm{P}=2.093$ ), which shows insignificant difference between the two groups. Similarly, the numbers of sag curves per mile for the treated sections was 1.62 compared to 1.41 for the non-treated locations (tSag $=1.568$, $\mathrm{P}=0.133$ ), which shows insignificant difference between the two groups.

Horizontal Alignment Properties: The width of the travel way was mostly identical throughout the study sections, 12 feet per lane with 6-8ft shoulder widths. It should be noted that the number of horizontal curves per mile and the Curvature Change Rate (CCR) were used as indices to describe the overall horizontal alignment of the roadway sections. The CCR is defined as the sum of the absolute values of the angular changes in the horizontal alignment of the roadway section divided by the total length of the road section.

Table 3 provides detailed information about the horizontal alignment characteristics of the existed headlight sections and the comparable non-headlight sign sections used in this study.

\section{Table 2: Vertical Alignment Characteristics of Headlight and Non -Headlight Sections}

\begin{tabular}{|c|c|c|c|c|c|c|c|}
\hline \multirow[b]{2}{*}{ Road Name } & \multirow[b]{2}{*}{$\begin{array}{l}\text { Section Length } \\
\text { (miles) / Status }\end{array}$} & \multicolumn{3}{|c|}{ Crest Vertical Curves } & \multicolumn{3}{|c|}{ Sag Vertical Curves } \\
\hline & & $\begin{array}{c}\text { \# of } \\
\text { Curves }\end{array}$ & $\begin{array}{l}\text { Avg. Curve } \\
\text { Length (ft) }\end{array}$ & $\begin{array}{c}\text { \# of } \\
\text { Curves / } \\
\text { Mile }\end{array}$ & $\begin{array}{c}\text { Total \# of } \\
\text { Curves }\end{array}$ & $\begin{array}{l}\text { Avg. Curve } \\
\text { Length (ft) }\end{array}$ & $\begin{array}{c}\text { \# of } \\
\text { Curves / } \\
\text { Mile }\end{array}$ \\
\hline US287 & 22.2 / Treated & 29 & 940 & 1.30 & 31 & 657 & 1.40 \\
\hline $\begin{array}{l}\text { US287 / } \\
\text { WY789 }\end{array}$ & 11.2 / Treated & 22 & 1136 & 1.96 & 23 & 778 & 1.98 \\
\hline US287 & 10 / Treated & 14 & 1051 & 1.40 & 18 & 456 & 1.80 \\
\hline WY220 & 14 / Treated & 17 & 1024 & 1.21 & 19 & 884 & 1.36 \\
\hline WY59 & 25 / Treated & 33 & 900 & 1.32 & 45 & 493 & 1.80 \\
\hline US20/26 & 49.3 / Treated & 79 & 466 & 1.60 & 72 & 432 & 1.46 \\
\hline WY28 & 43.8 / Treated & 57 & 996 & 1.30 & 66 & 706 & 1.51 \\
\hline WY22 & 17 / Non-treated & 24 & 621 & 1.41 & 27 & 574 & 1.58 \\
\hline US 191 & 163 / Non-treated & 205 & 701 & 1.26 & 222 & 554 & 1.36 \\
\hline US 278 & 100 / Non-treated & 33 & 936 & 0.33 & 38 & 636 & 0.38 \\
\hline WY 59 & 75 / Non-treated & 87 & 996 & 1.16 & 90 & 594 & 1.2 \\
\hline WY 220 & 117 / Non-treated & 135 & 968 & 1.15 & 151 & 737 & 1.29 \\
\hline US85 & 240 / Non-treated & 341 & 915 & 1.42 & 386 & 607 & 1.61 \\
\hline US 30 & 100 / Non-treated & 110 & 959 & 1.1 & 121 & 761 & 1.21 \\
\hline US 189 & 107 / Non-treated & 152 & 880 & 1.42 & 154 & 651 & 1.44 \\
\hline US $26 \mathrm{II}$ & 41 / Non-treated & 56 & 1121 & 1.36 & 61 & 652 & 1.48 \\
\hline WY 789 & 53 / Non-treated & 70 & 783 & 1.32 & 83 & 552 & 1.56 \\
\hline WY 414 & 47 / Non-treated & 89 & 690 & 1.89 & 78 & 611 & 1.65 \\
\hline WY 387 & 58 / Non-treated & 53 & 1302 & 0.91 & 64 & 779 & 1.1 \\
\hline US 14 & 100 / Non-treated & 156 & 654 & 1.56 & 164 & 573 & 1.64 \\
\hline US 16 & 106 / Non-treated & 64 & 764 & 0.60 & 74 & 524 & 0.70 \\
\hline US 191 & 51 / Non-treated & 100 & 803 & 1.96 & 104 & 588 & 2.03 \\
\hline WY 120 & 81 / Non-treated & 99 & 1140 & 1.22 & 103 & 724 & 1.27 \\
\hline US 26 & 38 / Non-treated & 49 & 857 & 1.28 & 59 & 544 & 1.55 \\
\hline US 212 & 35 / Non-treated & 75 & 414 & 2.14 & 78 & 429 & 2.22 \\
\hline $\begin{array}{c}\text { Total } \\
\text { treated }\end{array}$ & 175.5 & $\begin{array}{l}\text { Average } \\
\text { treated }\end{array}$ & 748.0 & 1.44 & - & 629.4 & 1.62 \\
\hline $\begin{array}{c}\text { Total } \\
\text { non-treated }\end{array}$ & 1529 & $\begin{array}{c}\text { Average } \\
\text { non-treated }\end{array}$ & 861.3 & 1.31 & - & 616.1 & 1.41 \\
\hline
\end{tabular}

Table 4 provides a summary statistics and a comparison of the horizontal alignment characteristics for the treated and non-treated sections. Comparing the two used indices between the treated and non-treated, they provide nearly similar horizontal alignment characteristics. The average number of curves per mile for untreated sections was $8.9 \%$ less than for treated sections, where the 
average number of curves per mile for non-treated sections was 1.02 compared to 1.12 for treated sections. In addition, the CCRs provide a difference of $13.6 \%$ between the two sets of sections, which provides nearly similar horizontal alignment characteristics for them. In addition, unequal sample t-test was conducted to check the difference between the two groups. The results showed that both groups are not significantly different, $(\mathrm{t}$ \# of Curves $=-1.457 ; \mathrm{P}=0.160$, $\mathrm{t}$ CCR $=-1.927 ; \mathrm{P}=0.068$ )

Table 3: Horizontal Alignment Characteristics of Headlight and Non -Headlight Sections

\begin{tabular}{|c|c|c|c|c|c|c|c|c|c|c|}
\hline Road name & $\begin{array}{l}\text { Impleme } \\
\text { nt Year }\end{array}$ & $\begin{array}{l}\text { Start } \\
\text { MP }\end{array}$ & $\begin{array}{l}\text { End } \\
\text { MP }\end{array}$ & $\begin{array}{l}\text { Section } \\
\text { Length } \\
\text { (mile) }\end{array}$ & $\begin{array}{l}\text { No of } \\
\text { curves }\end{array}$ & $\begin{array}{c}\text { Curves / } \\
\text { mile }\end{array}$ & $\begin{array}{c}\text { Avg. } \\
\text { Deflectio } \\
\text { n Angle }\end{array}$ & CCR & $\begin{array}{c}\text { Avg. } \\
\text { Curve } \\
\text { Length }\end{array}$ & $\begin{array}{l}\text { Avg. } \\
\text { Radius }\end{array}$ \\
\hline US287 & 2001 & 402.6 & 424.8 & 22.2 & 26 & 1.17 & 21.35 & 24.03 & 1720 & 5943 \\
\hline $\begin{array}{l}\text { US287 / } \\
\text { WY789 }\end{array}$ & 1994 & 2.4 & 13.6 & 11.2 & 12 & 1.07 & 10.58 & 11.35 & 626 & 4119 \\
\hline US287 & 2001 & 23 & 33 & 10 & 3 & 0.30 & 7.40 & 2.21 & 865 & 7583 \\
\hline WY220 & 2012 & 88 & 102 & 14 & 13 & 0.93 & 16.98 & 15.78 & 1388 & 6502 \\
\hline WY59 & 2012 & 76 & 101 & 25 & 7 & 0.28 & 9.60 & 2.69 & 800 & 4911 \\
\hline US20/26 & 2002 & 50.69 & 100 & 49.3 & 24 & 0.48 & 17.11 & 8.33 & 2240 & 7400 \\
\hline WY28 & 2010 & 24.4 & 68.2 & 43.8 & 51 & 1.16 & 26.09 & 30.40 & 1168 & 4417 \\
\hline WY22 & -- & 0 & 17 & 17 & 61 & 3.64 & 39.75 & 144.97 & 496 & 1810 \\
\hline US 191 & -- & 0 & 163 & 163 & 166 & 1.02 & 27.62 & 28.29 & 1202 & 4767 \\
\hline US 278 & -- & 325 & 425 & 100 & 27 & 0.27 & 21.30 & 5.75 & 1676 & 5748 \\
\hline WY 59 & -- & 0 & 75 & 75 & 39 & 0.52 & 24.41 & 12.69 & 1571 & 5932 \\
\hline WY 220 & -- & 0 & 117 & 117 & 76 & 0.65 & 20.83 & 13.53 & 1802 & 7034 \\
\hline US85 & -- & 16 & 256 & 240 & 180 & 0.75 & 22.09 & 16.56 & 1376 & 6151 \\
\hline US 30 & -- & 0 & 100 & 100 & 98 & 0.98 & 22.45 & 22 & 1600 & 6078 \\
\hline US 189 & -- & 15 & 122 & 107 & 107 & 1 & 24.88 & 24.88 & 1422 & 5282 \\
\hline US 26 II & -- & 0 & 41 & 41 & 23 & 0.56 & 10.73 & 6.022 & 788 & 5276 \\
\hline WY 789 & -- & 0 & 53 & 53 & 23 & 0.72 & 19.14 & 13.72 & 1019 & 3976 \\
\hline WY 414 & -- & 93 & 140 & 47 & 63 & 1.36 & 29.99 & 40.83 & 1357 & 4648 \\
\hline WY 387 & -- & 93 & 151 & 58 & 60 & 1.03 & 25.60 & 26.48 & 1346 & 3722 \\
\hline US 14 & -- & 0 & 100 & 100 & 171 & 1.71 & 24.42 & 41.76 & 830 & 3372 \\
\hline US 16 & -- & 153 & 259 & 106 & 51 & 0.48 & 18.18 & 8.74 & 1315 & 8508 \\
\hline US 191 & -- & 500 & 551 & 51 & 98 & 1.92 & 35.52 & 68.26 & 1170 & 2802 \\
\hline WY 120 & -- & 0 & 81 & 81 & 139 & 1.72 & 19.31 & 33.29 & 1133 & 5063 \\
\hline US 26 & -- & 0 & 38 & 38 & 33 & 0.86 & 21.05 & 18.28 & 979 & 4307 \\
\hline \multirow{2}{*}{$\begin{array}{c}\text { Descriptio } \\
\mathbf{n}\end{array}$} & \multicolumn{3}{|c|}{ Headlight sign sections } & Non-hea & dlight sign & sections & \multirow{2}{*}{\multicolumn{4}{|c|}{$\begin{array}{l}\% \text { difference between treated and } \\
\text { non-treated sections }\end{array}$}} \\
\hline & Min & Mean & Max & Min & Mean & Max & & & & \\
\hline $\begin{array}{l}\# \text { curves / } \\
\text { mile }\end{array}$ & 0.28 & 1.12 & 3.64 & 0.27 & 1.02 & 1.92 & \multicolumn{4}{|c|}{$-8.9 \%$} \\
\hline CCR & 2.21 & 30.82 & 145 & 5.75 & 26.64 & 72 & \multicolumn{4}{|c|}{$-13.6 \%$} \\
\hline $\begin{array}{l}\text { Avg. Curve } \\
\text { length }\end{array}$ & 496 & 1083 & 2240 & 337 & 1230.77 & 1802 & \multicolumn{4}{|c|}{$13.6 \%$} \\
\hline Avg. Radius & 1810 & 5249 & 7583 & 563 & 4895.8 & 8508 & \multicolumn{4}{|c|}{$-6.7 \%$} \\
\hline
\end{tabular}

\section{Data description and preparation}

Three datasets were used to achieve the objectives of this study. Crash data were extracted from the Wyoming Critical Analysis Reporting Environment (CARE). It should be noted that crash data in the CARE package do not include Vehicle Identification Numbers (VINs). VINs are needed to identify vehicles with automatic Daytime Running Lights (DRLs) in the crash reports. A full list of VINs for 
vehicles involved in crashes was obtained from WYDOT and matched to crashes in the CARE package. Ten years of traffic data (2004-2013) were also acquired from WYDOT. A Total number of 106,622 crashes for the years 2004-2013 were collected with complete VINs.

Only target crashes, i.e., head-on and opposite side-swipe crashes, with the following criteria were considered in the study; crashes occurred on 2-lane rural highways, posted speed is greater than 55 $\mathrm{mph}$, daytime only crashes since headlight signs countermeasure targets daytime crashes, no alcohol or drug involved, and no animal crashes. The dataset was further split into; crashes for locations with headlight signs, and crashes for locations without headlight signs.

As mentioned earlier, VIN dataset was used to evaluate the safety efficacy of headlight sign based on the presence of automatic Day Time Running Lights (DRLs) in the crashed vehicle. To identify what headlight technology a vehicle might have, the website: www.decodethis.com was used. This website classifies DRL into three groups: "Standard DRL", "No DRL", and "Optional DRL". A total of 6713 VINs (6230 randomly sampled target crashes for locations without headlight signs, and all 483 target crashes occurred on locations with headlight signs) were checked to determine the type of headlight technology equipped in vehicles involved in crashes. Only crash data belongs to the "No DRL" and "Standard DRL" were used in the analysis. Figure 3 shows the crash rates, frequencies, and percentages according to DRL equipment for locations with and without headlight signs. The data showed that $70 \%$ and $77 \%$ of vehicles involved in crashes in locations with and without headlight signs are non-DRL equipped vehicles, respectively.

Figure 3: Rates, frequencies and percentages of total and target crashes



A) Crashes per mile for location without headlight signs

B) Crash frequencies and percentage for locations without headlight signs

C) Crashes per mile for location with headlight signs 
D) Crash frequencies and percentage for locations with headlight signs

Table 5 provides descriptive statistics of rates for both total and target crashes for the headlight and non-headlight sign sections (2004-2013). While WY28 experienced the highest number of total crashes per million vehicle miles travelled (MVMT) among all the headlight sections, the US287 had the highest rate of head-on and opposite sideswipe crashes (target crashes). Moreover, the table shows that while the non-treated sections had slightly higher crash rates per MVMT for total crashes, the treated sections had higher crash rates for target crashes on average.

\section{Data limitations and availability}

The headlight signs were implemented on different years as shown in Figure 2. Early implementation of the headlight sign countermeasure was in 1994 on an 11-mile section on US287/WY789. The recent implementation of the countermeasure took place in 2012 at two different locations. It is worth mentioning that the AADT data for Wyoming's highway road network are available from 2003 till present only. This would introduce limitations to conduct observational before-after studies for this specific countermeasure as there is no AADT data exist for the before period. In addition, compliance data were only collected in 2014.This led in utilizing the odds ratio and ratio of the odds ratio analyses as the major methodologies adopted in this study.

Table 5: Descriptive Statistics of Crash Rates for Headlight and Non-Headlight Sign Sections

\begin{tabular}{|c|c|c|c|c|c|c|c|c|c|c|}
\hline \multirow[t]{2}{*}{ Segment } & \multicolumn{4}{|c|}{$\begin{array}{l}\text { Crash rate for total crashes per MVMT } \\
\text { (from 2004 to 2013) }\end{array}$} & \multirow[t]{2}{*}{$\begin{array}{l}\text { Total \# of } \\
\text { crashes }\end{array}$} & \multicolumn{4}{|c|}{$\begin{array}{l}\text { Crash rate for target Crash per MVMT } \\
\text { (from 2004 to 2013) }\end{array}$} & \multirow{2}{*}{$\begin{array}{c}\text { Total } \\
\text { \# of } \\
\text { Targe } \\
\text { t } \\
\text { Crash } \\
\text { es }\end{array}$} \\
\hline & Min & Mean & Max & St.dev & & Min & Mean & Max & St.dev & \\
\hline US $287^{*}$ & 0.66 & 1.04 & 1.38 & 0.26 & 308 & 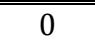 & 0.05 & "0.11 & "0.03 & 15 \\
\hline $\begin{array}{c}\text { US287 / WY } \\
789 *\end{array}$ & 0 & 0.97 & 2.18 & 0.64 & 33 & 0 & 0.03 & 0.28 & 0.08 & 1 \\
\hline US $287^{*}$ & 0 & 0.72 & 1.82 & 0.51 & 23 & 0 & 0.05 & 0.28 & 0.11 & 2 \\
\hline WY 220 * & 0.75 & 1.03 & 1.36 & 0.23 & 157 & 0 & 0.02 & 0.12 & 0.04 & 3 \\
\hline WY 59 * & 0.4 & 0.71 & 1.02 & 0.18 & 252 & 0 & 0.03 & 0.08 & 0.03 & 11 \\
\hline US20/26* & 0.42 & 0.68 & 0.9 & 0.16 & 283 & 0 & 0.03 & 0.07 & 0.02 & 11 \\
\hline WY 28 * & 1.22 & 2.04 & 3.36 & 0.57 & 426 & 0 & 0.04 & 0.12 & 0.04 & 8 \\
\hline WY22 & 0.92 & 1.38 & 1.82 & 0.34 & 741 & 0.016 & 0.07 & 0.20 & 0.06 & 36 \\
\hline US 191 & 0.7 & 0.97 & 1.27 & 0.20 & 2243 & 0 & 0.01 & 0.03 & 0.01 & 28 \\
\hline US 278 & 0.31 & 0.45 & 0.55 & 0.06 & 1072 & 0 & 0.01 & 0.01 & 0.003 & 17 \\
\hline WY 59 & 3.27 & 4.79 & 6.4 & 1.03 & 3153 & 0.016 & 0.05 & 0.11 & 0.03 & 35 \\
\hline WY 220 & 0.59 & 0.78 & 0.96 & 0.11 & 2725 & 0 & 0.01 & 0.02 & 0.01 & 31 \\
\hline US85 & 0.45 & 0.58 & 0.79 & 0.09 & 1456 & 0.003 & 0.01 & 0.02 & 0.004 & 25 \\
\hline US 30 & 0.7 & 0.89 & 1.29 & 0.16 & 636 & 0 & 0.03 & 0.08 & 0.02 & 21 \\
\hline US 189 & 0.65 & 0.8 & 0.92 & 0.08 & 664 & 0 & 0.01 & 0.03 & 0.01 & 7 \\
\hline US 26 II & 0.48 & 0.96 & 1.58 & 0.34 & 126 & 0 & 0.03 & 0.07 & 0.03 & 3 \\
\hline WY 789 & 0.69 & 0.99 & 1.42 & 0.26 & 296 & 0 & 0.04 & 0.08 & 0.03 & 13 \\
\hline WY 414 & 0.59 & 0.81 & 1.31 & 0.22 & 258 & 0 & 0.01 & 0.03 & 0.01 & 3 \\
\hline WY 387 & 0.56 & 0.87 & 1.26 & 0.22 & 283 & 0 & 0.03 & 0.06 & 0.02 & 10 \\
\hline US 14 & 0.55 & 0.71 & 0.85 & 0.09 & 1203 & 0 & 0.002 & 0.01 & 0.004 & 3 \\
\hline US 16 & 0.48 & 0.89 & 1.27 & 0.23 & 477 & 0 & 0.01 & 0.02 & 0.01 & 4 \\
\hline US 191 & 0.46 & 0.93 & 1.66 & 0.35 & 257 & 0 & 0.01 & 0.07 & 0.02 & 4 \\
\hline WY 120 & 0.69 & 1.05 & 1.47 & 0.22 & 453 & 0 & 0.01 & 0.02 & 0.01 & 3 \\
\hline US 26 & 0.68 & 1.02 & 1.34 & 0.22 & 288 & 0 & 0.02 & 0.06 & 0.02 & 7 \\
\hline $\begin{array}{l}\text { Average } \\
\text { treated }\end{array}$ & 0.49 & 1.03 & 1.72 & 0.36 & 211.71 & 0 & 0.04 & 0.15 & 0.05 & 7.29 \\
\hline $\begin{array}{c}\text { Average non- } \\
\text { treated }\end{array}$ & 0.75 & 1.11 & 1.54 & 0.25 & 960.65 & 0 & 0.02 & 0.05 & 0.02 & 14.71 \\
\hline
\end{tabular}

With the increase in number of vehicles equipped with DRLs and automatic low-beam headlights, many drivers does not comply with regulatory headlight signs. To investigate the effect of the DRL technology penetration on the safety effectiveness of regulatory headlight signs, information about compliance to the headlight light sign and the existence of DRL technology for the crashed vehicles in 
the before and after periods are essential. However, it is impossible to obtain such information for the historical crash data.

\section{Safety effectiveness of headlight signs}

As discussed earlier, there is a difference between the newly DRL-equipped vehicles and manually turning on headlights. This forms four different scenarios that should be considered in analyzing Wyoming daytime crashes on rural two-lane highways. The four different scenarios were studied using a case-control method, forming a 2 by 2 contingency table. A comparison of daytime crashes for a set of passenger vehicles equipped with DRLs and vehicles without DRLs on roadways sections with and without headlight signs was conducted. In order to quantify how strongly the presence of DRL is associated with the existence of headlight signs for crashes in two way two lane highways, simple odds, odds ratios, and ratio of odds ratio were calculated in this study. The utilized analyses will adjust for a variety of exogenous factors enabling us to evaluate the safety benefit of headlight signs with the presence and absence of DRL.

This approach is commonly utilized in the literature to quantify the safety benefits of DRL because of its case-control design flexibility and capability to analyze crashes involving DRL-equipped vehicle vs crashes for non-DRL equipped vehicle (Tessmer, 2004; Wang, 2008; National Highway Traffic Safety Administration, 2000). Recent studies have utilized the ratio of odds ratio as their primary methodology to evaluate the safety effectiveness of DRL for two main reasons; 1 ) it can easily account for confounding factors that may influence the effect of DRL benefits, 2) the sensitivity of this method with small sample size provides a more conservative results (Pierowicz et al., 2011). That is the case in this study with the limited number of treated sites.

The Highway Safety Manual (HSM, 2010) provides two main methods to evaluate the safety effectiveness of implemented treatments; 1) observational before-after studies, and 2) observational cross-sectional studies (HSM, 2010). The observational before-after studies have four main approaches a) The Naïve before-after study, b) Observational before-after studies using Empirical Bayes (EB), c) Observational before/after studies using a comparison group, and d) Observational before-after studies to evaluate the shift in collisions. Observational cross-sectional studies are used mainly where observational before-after cannot be implemented. It compares the safety performance of sites with implemented treatment with other untreated sites using regression models.

The use of Observational Before-after design may not be always possible or practical because installation dates for a treatment of interest may not be available, there are no enough before-after data, or there are no enough treated sites. The HSM recommends at least 3 to 5 years of crash data in the before and after periods for the implemented treatment.

Among the four before/after studies used to evaluate the safety effectiveness of certain countermeasure, the EB is considered the most reliable method. The expected average crash frequency utilizing the safety performance functions (SPF) for the roadway facility is used in the analysis. That strengthen the results obtained for this method as it is the only method accounting for the regression to the mean bias (RTM). The produced expected crashes in the before and after periods are not subjected to over- or under-estimation of crashes due to possible time limitation. The naïve method provides a rough evaluation of treatments as it does not account for the RTM bias. It could also underestimate or overestimate the safety benefits of a certain countermeasure.

It should be mentioned that in a case-control study, cases and controls are selected based on outcome status (e.g., crash or no crash, DRL equipped vehicles or non-DRL equipped vehicles) and then determine prior treatment (or risk factor) within each outcome group. Case-control studies and Crosssectional studies, both use cross-sectional data and hence, they should not be confused for one another.

The feasibility of using observational before-after with Empirical Bayes (EB) and cross-sectional analyses was investigated, however, the results obtained were not significant and hence are not presented in this study. The before-after study was very limited in terms of the number of sites analyzed because of the limitation in crash and AADT data. The before-after with EB analysis indicated that headlight signs are not effective in reducing target crashes and the calculated CMFs were not statistically significant. The cross-sectional analysis attempted in this study took into consideration weather, traffic characteristics, and roadway geometry to compare the safety efficacy of headlight signs on treated sections with twenty non-treated sections. Negative binomial (NB) and Zero-Inflated Poisson (ZIP) 
models were calibrated for total, target, fatal, injury, and PDO crashes. Segmentation for the analysis was developed according to homogeneity in vertical and horizontal roadway geometric characteristics of the segments (Ahmed et al., 2011). The results were in agreement with the before-after EB method. It is worth mentioning that observational studies may not be suitable for this study because of the time and space domains that the countermeasure might have an impact on. In addition, the inclusion of the compliance and DRL technology penetration rates cannot be directly incorporated in either an observational before-after nor cross-sectional study design.

\section{Simple Odds Ratio and Ratio of Odds Ratio Analysis}

Because of the nature of the headlight sign countermeasure and the limited number of treated roadway sections, simple odds, and ratio of odds ratios were the primary statistics utilized in this study. Odds ratio indicates the increased/decreased likelihood of a crash occurring when a treatment is present. It indicates the probability of event occurrence over the non-occurrence probability (Agresti et al., 2007). The case-controlled data were selected to conduct the analysis to control for the confounding factors, which could affect the real impact of the headlight signs. An odds ratio of less than 1.0 indicated a reduction in crashes, which imply a positive safety effect of the treatment and vice versa. Ratio of odds ratios has a stronger ability to control for the possible confounding factor than the simple odd ratio. Ratio of odds ratio would provide a more reliable a results (Pierowicz et al., 2011).

Several studies utilized the odds ratio to assess the safety effectiveness of using different safety treatments (Theeuwes \& Riemersma, 1995; Pepe et al., 2004; Guo et al., 2010). Equation 1 can be used to calculate the odds ratio (Sheskin, 2003). To evaluate the null hypothesis of the odds ratio, confidence intervals should be calculated. To obtain the confidence intervals for $95 \%$ confidence level, equation 2 and 3 were utilized. The Z-score for $95 \%$ confidence level multiplied by the square root of the standard error was added to / subtracted from the exponential transformation of the log transformation of odds ratio. To get the upper and lower confidence levels, the result of the above calculation was retransformed using the exponential (Sheskin, 2003).

Where:

$$
\begin{aligned}
& \text { OR }=\frac{\pi_{11} / \pi_{12}}{\pi_{21} / \pi_{22}} \\
& C I_{\text {upper }}=e^{\left[\ln (O R)+Z_{0.05} * \sqrt{S E}\right]} \\
& C I_{\text {lower }}=e^{\left[\ln (O R)-Z_{0.05} * \sqrt{S E}\right]}
\end{aligned}
$$

OR : The odds ratio

$\pi$ : The odds for each group category

Z0.05 : The Z-score for 95\% confidence level $=1.96$

SE $\quad$ : Standard Error and is obtained be the equation $\frac{1}{\pi_{11}}+\frac{1}{\pi_{12}}+\frac{1}{\pi_{21}}+\frac{1}{\pi_{22}}$

Table 6 represents the $2 * 2$ contingency table for the frequencies of the investigated crash types, DRL equipped state, and existence of headlight signs. It also shows the odds and the odds ratio values of the crashes for headlight and non-headlight sign locations by the DRL equipped state for the crashed vehicles. The odds for the locations with the headlight sign was $24 \%$ vs $20 \%$ for locations without headlight signs resulting in an odds ratio of 1.17 . This implies that locations with headlight signs receives 17\% more total crashes than locations without headlight signs, controlling for the DRL factor. The confidence intervals were calculated to range from 0.91 to 1.51 indicating no significant effect of having DRL in crash reduction for two way highways with the presence of headlight signs.

The same analysis was conducted for target crashes. Head-on and sides-wipe opposite crashes were investigated for the same locations to examine the effect of DRL with the presence of headlight

\begin{tabular}{|c|c|c|c|c|c|}
\hline Crash Type & Section description & $\begin{array}{l}\text { DRL equipped } \\
\text { Vehicles }\end{array}$ & $\begin{array}{l}\text { Non-DRL } \\
\text { equipped } \\
\text { Vehicles }\end{array}$ & Odds & $\begin{array}{l}\text { Odds } \\
\text { Ratio }\end{array}$ \\
\hline Total Crashes & with Headlight signs & 80 & 337 & $23.74 \%$ & 1.17 \\
\hline
\end{tabular}
signs for certain crash types in two way two lane highways.

Table 6: Two-Way Contingency Table with Odds and Odds Ratio for Total and Target Crashes 
Target Crashes

without Headlight signs with Headlight signs without Headlight signs

$\begin{array}{ccc}970 & 4799 & 20.21 \% \\ 4 & 32 & 12.50 \% \\ 95 & 429 & 22.14 \%\end{array}$

0.56

The odds for the locations with the headlight sign was $13 \%$ vs $22 \%$ for location without headlight signs for target crashes. An odds ratio of 0.56 was obtained. Which implies that locations with headlight signs experienced $44 \%$ less target crashes than locations without headlight signs, having DRL equipment controlled for. The confidence intervals were calculated to range from 0.19 to 1.63 . Confidence intervals indicate that there is no significant effect of having DRL on head-on and sideswipe opposite crashes for two way highways with the presence of headlight signs.

The NHTSA (2011) utilized the ratio of odds ratio (ROR) to show the effectiveness of using DRL technology in reducing crashes (Pierowicz et al., 2011). A case-control analysis using ROR was adopted in the study. Ratio of odds ratio (ROR) for the headlight sign as a safety countermeasure had a value of 0.45 , which indicates a $54.64 \%$ reduction in target crashes, controlling for DRL technology. However, the result from the ROR was not significant at 95\% significance level, as shown in Table 7.

\section{Table 7: Ratio of Odds Ratio Analysis for Headlight Sign Controlling for the DRL Technology}

\begin{tabular}{|c|c|c|c|c|c|}
\hline \multirow{8}{*}{ 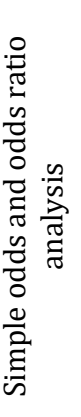 } & \multicolumn{5}{|c|}{ Headlight Locations } \\
\hline & & Target crashes & Control crashes & Odds & OR \\
\hline & DRL & 4 & 76 & 0.05 & \multirow{2}{*}{0.50} \\
\hline & No DRL & 32 & 305 & 0.10 & \\
\hline & \multicolumn{5}{|c|}{ Non-Headlight Locations } \\
\hline & \multicolumn{2}{|r|}{ Target crashes } & Control crashes & Odds & OR \\
\hline & DRL & 95 & 875 & 0.11 & \multirow{2}{*}{1.11} \\
\hline & No DRL & 429 & 4370 & 0.10 & \\
\hline \multirow{4}{*}{ 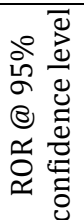 } & \multicolumn{2}{|c|}{ Lower bound } & ROR & \multicolumn{2}{|c|}{ Upper bound } \\
\hline & \multicolumn{2}{|c|}{0.11} & 0.45 & \multicolumn{2}{|l|}{1.97} \\
\hline & \multicolumn{2}{|c|}{ Lower bound \% } & Effectiveness \% & \multicolumn{2}{|c|}{ Upper bound \% } \\
\hline & \multicolumn{2}{|c|}{$-35.54 \%$} & $54.64 \%$ & \multicolumn{2}{|c|}{$84.82 \%$} \\
\hline
\end{tabular}

\section{Field study on current headlight signs compliance rate}

The purpose of the data collection is to quantify the existing compliance rate at the locations with headlight signs and to examine if there is any change in compliance rate among locations. Field data were also collected from locations without headlight signs in order to examine the actual effect of the headlight signs and to estimate an accurate compliance rate. Field data were collected from three locations with headlight signs (US287 M.P.405, WY220 M.P.96, and WY59 M.P.82) and two locations without headlight signs (US26 M.P.27 and US20/18 M.P.7). All the locations are classified as rural principle arterial roadways. A duration of minimum 4 hours up to 8 hours per location was utilized to collect compliance rates on the sections with headlight signs and the headlight use on sections without headlight signs. Based on the status of headlight and taillight, the percentages of DRL-equipped vehicles and manual use of headlights were estimated.

Figure 4 shows the percentage of vehicles equipped with DRL vs vehicles not equipped with DRL in the five data collection locations. The average percentage of vehicles equipped with automatic DRLs in the location with headlight signs was $44 \%$ while the percentage was $56 \%$ for non-DRL equipped vehicles. Also, the average percentage of non-DRL equipped vehicles in locations without headlight signs was higher than the DRL equipped vehicles. The percentages were $48 \%$ and $52 \%$, respectively. 
Figure 4: Percentage of Vehicles Equipped with DRL Vs Vehicles Non-DRL Equipped



\section{Compliance rates}

Compliance rates analysis was conducted for non-DRL equipped vehicles. The total average compliance rate was $25 \%$ for headlight sign sections and the use of manual headlights on non-headlight sign sections was $13 \%$ However, both percentages are low, the percentage of vehicles complying with the headlight signs are higher than those using their headlights on non-headlight sections. If an assumption that $13 \%$ of all roadway users who always turn on their headlights on sections with or without headlight signs could be made, then it could be assumed that only $12 \%$ of road users are complying with the headlight signs. In order to determine if there is a significant difference between the compliance rate on headlight sign sections and the rate of using headlights on non-headlight sign sections, a simple Z-test for proportions was conducted with "No difference in compliance rate between the two sections" hypothesis, Z=6.405 was obtained. Comparing the obtained Z-score with the Z-critical for a confidence level of $95 \%$, the null hypothesis is rejected, indicating that there is a significant difference between the two types of sections.

\section{Challenges and limitations}

Crashes are rare and random events. Crash frequency of head-on and opposite sideswipe crashes is evidently low on rural two-way two-lane highways in Wyoming. Whether the crashed vehicle is equipped with DRL or not is not provided in the data set, it was challenging to identify the DRL-equipped and non-DRL equipped vehicles in this study. The identification and verification of the DRL technology was performed manually by decoding the Vehicle Identification Number (VIN) data for all at-fault involved vehicles www.decodethis.com website. In this study, more than 6000 crashes were identified which was a very time consuming process.

The efficacy of the headlight sign is a compliance dependent countermeasure. Compliance rate data for historical data were not available, which limits the usage of observational studies. Moreover, the headlight sign is not a site-specific countermeasure, as the WYDOT restricted using the end of headlight section sign as it might deliver a false message during the night time. This could affect the safety benefits of headlight sign.

Other in-vehicle technologies, such as automatic sensor headlight, anti-lock braking systems, stability control systems, lane departure alarms, and proximity sensors alarms might work as confounding factors to this study. However, it is not possible to account for all the mentioned factors as they will provide more complexity to the study. Although the utilized methodologies seem simple and easy approaches, many limitations and challenges were overcome conducting this study. 


\section{Conclusions}

This study for the first time accounted for the compliance rate, and the penetration of the DRL technology in evaluating the safety effectiveness of regulatory headlight signs on mountainous rural two-lane highways. A variety of external factors were adjusted for using simple odds and ratio of odds ratios. Four different cases were considered in analyzing Wyoming daytime crashes on mountainous rural two-lane highways. Comparison between crashes for a set of passenger vehicles equipped and unequipped with DRLs on roadways sections with and without Headlight Signs was conducted using a case-control method. Three different approaches were used in the study including observational beforeafter with EB and cross-sectional analyses. However, results of ratio of odds ratio (ROR) analysis was only presented in this study due to its suitability to a behavioral-based countermeasure, i.e., headlight signs, over other approaches. The results of observational before-after and cross-sectional analyses showed no significant effect of the headlight signs. The design of the ROR analysis accounted for other confounding factors as the DRL equipped in vehicles and hence provided the most reliable results of the effect of the headlight signs.

The odds ratio analysis showed that $77 \%$ of vehicles involved in crashes were not equipped with DRL. There was no significant difference between DRLs and non-DRL equipped vehicles on sections with or without headlight signs on total and target crashes (head-on and sideswipe opposite crashes). This could be mistakenly explained that there are no added safety benefits of headlight signs. The field study showed a very low compliance rate of only $12 \%$ to the headlight signs. Headlight signs are behavioralbased countermeasure; compliance rates should be considered when evaluating the safety effectiveness of behavioral-based countermeasures such as headlight signs.

The results of the ROR showed that the headlight sign reduced the head-on and the opposite sideswipe crashes (target crashes). However, the results were not statistically significant at 95\% significance level. The vague safety benefits of headlight signs could be due to the few treated roadway sections, short treated segments, and low compliance rate for the headlight sign. This low compliance rate might be attributed to the poor design of the sign which might not be suitable for the rural nature of Wyoming. The fact that only one sign is installed at headlight section might explain the lack of effectiveness found at headlight signs' sections and the low compliance rate. In addition, the sign might be hard to notice, especially during adverse weather conditions, as the white color of the sign might be blended with the snowy white background.

\section{Recommendations}

Transportation agencies might need to consider different strategies to increase the compliance rates to such countermeasures. Different headlight sign designs and frequency of use on challenging mountainous rural highways should be considered to increase the compliance rate. Changing the sign design and increasing its posting frequency could be assessed in a controlled environment using a driving simulator. Law enforcement, traffic awareness campaigns, and legislations such as "wipers-on, headlights on" could be other measures to increase vehicle conspicuity on challenging roadway section and during inclement weather conditions.

\section{Appendix A. Supplementary material}

Supplementary data associated with this article can be found, in the online version, at https://jsdtl.sciview.net

\section{Acknowledgments}

This study was funded by the Federal Highway Administration (FHWA) and the Wyoming Department of Transportation (WYDOT) as part of Grant number FHWA-WY-16/03F. The authors would like to thank the WYDOT for providing the data that were used in this study. All opinions and results are solely those of the authors. 


\section{Citation information}

Ahmed, M. M., Gaweesh, S., Ksaibati, K., \& Rahman, Md. H. (2018). Assessing the impact of the compliance rate and daytime running lights penetration on the safety effectiveness of regulatory headlight use signs. Journal of Sustainable Development of Transport and Logistics, 3(1), 6-21. doi:10.14254/jsdtl.2018.3-1.1

\section{References}

Agresti, A. (2007). An introduction to categorical data analysis, 2nd ed. Hoboken.

Ahmed, M., Huang, H., Abdel-Aty, M., \& Guevara, B. (2011). Exploring a Bayesian hierarchical approach for developing safety performance functions for a mountainous freeway. Accident Analysis \& Prevention, 43(4), 1581-1589.

Arora, H., Collard, D., Robbins, G., Welbourne, E. R., \& White, J. G. (1994). Effectiveness of daytime running lights in Canada(No. TP 12298 (E),).

Automatic Traffic Recorder Report, (2013). Wyoming Department of Transportation. Transportation Planning Program.

Chen, C., \& Xie, Y. (2016). Modeling the effects of AADT on predicting multiple-vehicle crashes at urban and suburban signalized intersections. Accident Analysis \& Prevention, 91, 72-83.

Dong, C., Nambisan, S. S., Richards, S. H., \& Ma, Z. (2015). Assessment of the effects of highway geometric design features on the frequency of truck involved crashes using bivariate regression. Transportation Research Part A: Policy and Practice, 75, 30-41.

Elvik, R. (1993). The effects on accidents of compulsory use of daytime running lights for cars in Norway. Accident Analysis \& Prevention, 25(4), 383-398.

Elvik, R. (1996). A meta-analysis of studies concerning the safety effects of daytime running lights on cars. Accident Analysis \& Prevention, 28(6), 685-694.

Farmer, C. M., \& Williams, A. F. (2002). Effects of daytime running lights on multiple-vehicle daylight crashes in the United States. Accident Analysis \& Prevention, 34(2), 197-203.

Guo, F., Klauer, S. G., McGill, M. T., \& Dingus, T. A. (2010). Evaluating the relationship between nearcrashes and crashes: Can near-crashes serve as a surrogate safety metric for crashes?.

Hansen, L. K. (1993). Daytime running lights in Denmark-Evaluation of the safety effect. Danish Council of Road Safety Research. Copenhagen.

Holló, P. (1998). Changes in the legislation on the use of daytime running lights by motor vehicles and their effect on road safety in Hungary. Accident Analysis \& Prevention, 30(2), 183-199.

National Research Council (US). Transportation Research Board. Task Force on Development of the Highway Safety Manual, \& Transportation Officials. Joint Task Force on the Highway Safety Manual. (2010). Highway safety manual (Vol. 1). AASHTO. Retrieved February 2017 from https://safety.fhwa.dot.gov/roadway_dept/.

Knight, I., Sexton, B., Bartlett, R., Barlow, T., Latham, S., \& McCrae, I. (2006). Daytime Running Lights (DRL): A review of the reports from the European Commission.

MUTCD. (2009). Manual on uniform traffic control devices (MUTCD). Federal Highway Administration, Washington, DC.

National Highway Traffic Safety Administration. (2000). A preliminary assessment of the crash-reducing effectiveness of passenger car daytime running lamps. US Department of Transportation, Washington, DC, Technical Report DOT HS, 808, 645.

Pepe, M. S., Janes, H., Longton, G., Leisenring, W., \& Newcomb, P. (2004). Limitations of the odds ratio in gauging the performance of a diagnostic, prognostic, or screening marker. American journal of epidemiology, 159(9), 882-890. 
Pierowicz, J., Gawron, V., Wilson, G., \& Bisantz, A. (2011). The Effects of Motor Vehicle Fleet Daytime Running Lights (DRL) on Motorcycle Conspicuity (No. HS-811 504).

Qin, X., Ivan, J. N., \& Ravishanker, N. (2004). Selecting exposure measures in crash rate prediction for two-lane highway segments. Accident Analysis \& Prevention, 36(2), 183-191.

Rumar, K. (1980). Running lights-conspicuity, glare and accident reduction. Accident Analysis \& Prevention, 12(2), 151-157.

Sheskin, D. J. (2003). Handbook of parametric and nonparametric statistical procedures. crc Press.

Sparks, G. A., Neudore, R. D., Smith, A. E., Wapman, K. R., \& Zador, P. L. (1993). The effect of daytime running lights on crashes between two vehicles in Saskatchewan: a study of a government fleet. Accident Analysis \& Prevention, 25(5), 619-625.

Tessmer, J. M. (2004). An assessment of the crash-reducing effectiveness of passenger vehicle daytime running lamps (DRLs). NHTSA, Washington, DC.

Theeuwes, J., \& Riemersma, J. (1995). Daytime running lights as a vehicle collision countermeasure: the Swedish evidence reconsidered. Accident Analysis \& Prevention, 27(5), 633-642.

Wainwright, W. S. (2005). Synthesis of Non-MUTCD Traffic Signing (No. FHWA-HOP-06-074).

Wang, J. S. (2008). The effectiveness of daytime running lights for passenger vehicles. National Highway Traffic Safety Administration.

Williams, A. F., \& Lancaster, K. A. (1995). The prospects of daytime running lights for reducing vehicle crashes in the United States. Public Health Reports, 110(3), 233.

WSHSP, 2012. Wyoming Highway Safety Management System Committee. (2012). Wyoming Strategic Highway Safety Plan.

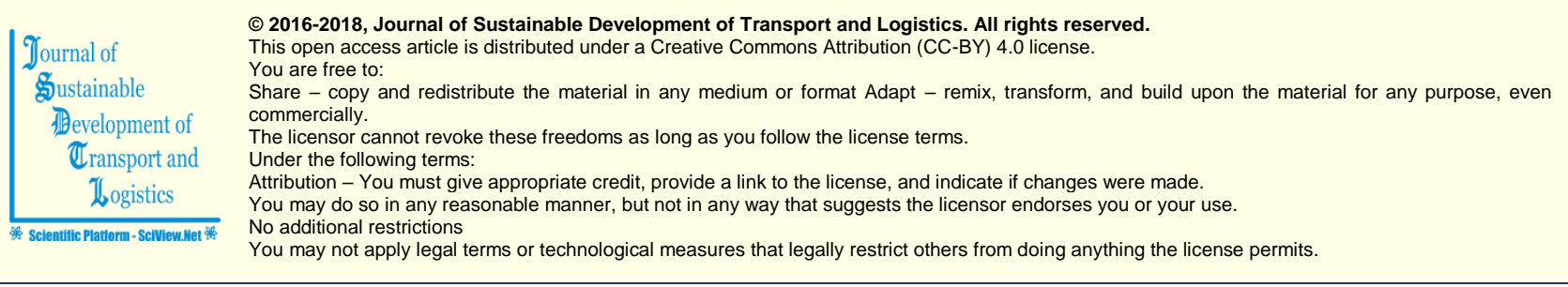

Journal of Sustainable Development of Transport and Logistics (ISSN: 2520-2979) is published by Scientific Publishing House "CSR", Poland, EU and Scientific Publishing House "SciView", Poland, EU

Publishing with JSDTL ensures:

- Immediate, universal access to your article on publication

- High visibility and discoverability via the JSDTL website

- Rapid publication

- Guaranteed legacy preservation of your article

- Discounts and waivers for authors in developing regions

Submit your manuscript to a JSDTL at https://jsdtI.sciview.net/ or submit.jsdt|@sciview.net 